\title{
AN ANALYSIS OF THE RESEARCH ON FACULTY DEVELOPMENT FOR ONLINE TEACHING AND IDENTIFICATION OF NEW DIRECTIONS
}

\author{
Author
}

\begin{abstract}
This article presents the results of an extensive review of the published literature on faculty development for online teaching. This review included 68 articles and five books, which were reviewed to identify elements of the training and the findings (e.g., theoretical bases, training aims and organization, content of training, nature of sample (number and type of participants), outcome measures used. The emphasis was not on the recommendations of the authors, but the methods of arriving at the findings. The review produced seven insights, from the importance of basing faculty development on theory, the frequency of publications that present models of faculty development for online teaching, the need to disentangle treatments, the need for rigorous evaluations, and the importance of considering individual faculty differences, designing and evaluating faculty development with specific outcome measures, and considering cost (either cost-efficiency or cost-effectiveness) when evaluating faculty development programs.
\end{abstract}

\section{KEYWORDS}

Faculty development, elements of training, theory, evaluation, outcome measures, cost

\section{INTRODUCTION}

What can we learn from the literature on faculty development that can improve our efforts to help faculty learn how to teach online? This question guided a review and analysis of the research and theoretical literature that will move from research on pre-Internet faculty development efforts to faculty development for online teaching, evaluate what we know against what we need to know, and finally, identify ways to increase what we know about how best to help faculty make the transition to online teaching. This is a lot of ground to cover, but understanding the issues involved in both faculty development and the theories and models currently in use is essential to arriving at some clear, understandable, and testable directions for the future.

Faculty development plays a role in the Sloan Consortium's [1] five pillars of quality. Faculty satisfaction is one of those pillars, which stresses the importance of faculty satisfaction with the online teaching experience and the faculty's commitment to improving what they do in their online courses. Sloan-C characterizes faculty satisfaction as resulting from institutional support (also rewards and involvement in governance), which in turn is defined as the opportunity for "training in online instructional skills" $(1, \mathbf{q 5})$. Thus, faculty development in online teaching is a critical foundation for quality online education and justified the creation by Sloan-C of an advisory panel of practitioners and researchers focused on faculty satisfaction, development, and support (http://sloanconsortium.org/jaln_advisory panel fs). As a first step in the work of the advisory panel, it was critical to identify the current state of knowledge for faculty development for online teaching, which is the aim and purpose of the research that follows. 


\section{REVIEW OF LITERATURE}

\section{A. Faculty Development}

\section{Before Online Teaching}

Since the formation of higher education institutions, faculty development may have always been part of a faculty person's duties, albeit characterized as staying abreast of the content matter taught by the instructor. In time, faculty development efforts became more organized but differed over time in focus. Sorcinelli et al. [2] proposed five distinct historical periods for faculty development efforts. The 1950s and 1960s were the age of the scholar and focused on research skills and productivity. The 1960s and 1970s were the age of the teacher and focused on improving teaching skills of the faculty. The 1980s were the age of the developer, which recognized the expertise of faculty developers whose efforts formalized and extended faculty development programs. The 1990s were the age of the learner, which recognized the shift in focus from teaching to student learning in higher education. The current era is the age of the network, which focuses on collaboration across faculty to encourage interdisciplinarity and more recently focuses on the electronic network - the Internet - and assisting faculty to learn how to best use technology for face-to-face courses and ultimately fully online courses.

Several current guides to faculty development help define the enterprise and provide guidance for organizing and implementing faculty development efforts. Sorcinelli et al. [2] focus on future directions and priorities for faculty development - where online teaching is mentioned - and Gillespie and Robertson [3] deal more with faculty development as an important service within an institution. Cook and Kaplan [4] stress the ways a teaching center can not only provide essential faculty development but also create a culture of teaching. Schroeder [5] calls on faculty developers to revision their role as one of organizational development. While $[3,4,5]$ include a single chapter in each guide on use of technology, these chapters may provide insufficient guidance to a unit specifically charged with helping faculty teach online. Although all of these guides are excellent primers on the faculty development enterprise in higher education, none are specifically directed to the specific problems of faculty development for online teaching. For this type of information, research articles found in various journals may be more helpful.

Currently, faculty development primarily focuses on teaching, including use of problem-based learning [6], use of interdisciplinary instruction for diversity courses [7], a plan for achieving diversity [8], teaching science in higher education [9], teaching marketing education [10], teaching clinicians, medical doctors, or medical educators $[11,12]$, and addressing demands that may be different for faculty at different career stages [13]. It is likely there are additional uses. As may be clear from this list, the faculty development effort may be focused on one preferred pedagogy being promoted (e.g., problem-based learning, use of case studies) or one discipline (science, medical education) and may not address faculty needs for more pedagogies that work in many disciplines or general education level courses. In two national studies of community college faculty $[14,15]$, faculty development programs rarely addressed the variety of pedagogical challenges that these faculty faced on a daily basis.

Faculty development has also been used to help faculty with other duties, such as understanding and having confidence in their ability to conduct assessment [16], although it is difficult to unravel which segment or portion of the four-part workshop series described by the authors actually contributed to changes in the faculty. This last is a common criticism of many faculty development programs, which provide a number of activities but cannot detail which activity was the most effective or whether change was dependent on all activities working in concert. In fact, as this review makes clear, the literature seems to include many faculty development articles that are sometimes hortative ("we must teach better"), sometimes descriptive ("here's what we did"), and many with modest evaluations of the faculty development effort that are unable to unravel which specific activities are proven to work.

A relevant issue is how the faculty development initiative is organized and delivered; does it matter if the effort is centralized or decentralized, provided one-to-one, in workshops, or in classes? Certainly, there 
are arguments for all options. Watson and Grossman [17] argue for the effectiveness of consortia, cooperatives, and distributed models since each organization may reflect particular institutional values or needs or ways of conducting its business. Many faculty development models have been proposed as well: the Master Teacher Initiative [10], New England Center for Inclusive Teaching [18], and ResourceEnriched Learning Model [19]. Later in this literature review, we can find some authors (such as [20, 21] arguing for the use of online means to teach better ways of teaching in traditional classrooms, although the focus is not yet on learning to teach online. That development will be taken up in the next section.

What is evident in this abbreviated review of faculty development is the lack of clarity on organizational effectiveness, a comparison of models, a breaking apart of the models and workshops to understand which activities actually affect faculty behavior, and a better grasp of which outcomes measures might be worth capturing.

\section{For Online Teaching}

With the growth in online education, institutions of higher education have been "faced with the challenge of developing faculty who are ready, willing and able to teach in the online world" [22, p. 27]. Faculty developers have responded to this need with a wide ranging set of services and activities, so it is not surprising that faculty development for online teaching has been represented in the literature with the same diversity as for faculty development prior to online teaching. Publications propound on the different types of faculty development - from workshops to short courses, local and regional programs [23] - that originally had very narrow foci - from use of a specific course management system to learning how to do podcasts [24]. Only later did it become important to help faculty move away from face-to-face teaching methods toward more appropriate methods for online courses [25]. As a first stage, faculty were encouraged to add technology to existing face-to-face courses, and then to move to new technologies and pedagogies [25] useful for offering entire courses online.

Articles have been published on special efforts to help faculty learn how to teach with technologies in the sciences [26, 27], clinical education [23], science education [27], marketing education [28], teacher education [24], community colleges [29], and to implement cloud-based technologies across the disciplines [30]. An area of continuing interest is in helping faculty learn how to create community in an online course [31] given its tie to improving student retention.

Readers interested in thorough studies of the faculty online teaching experience from the point-of-view of the faculty person are encouraged to review Conceição [32], Major [33], and Meyer [34], among others. Conceição [32] found that faculty teaching online came to find the experience very rewarding in new ways. Major [33] found that faculty experienced a myriad of changes, from time demands to relationships with students, and needed support to help navigate these changes to their roles. Meyer [34] found that experienced online tenured or tenure-track faculty had found ways to improve the learning productivity (the amount or speed of learning) of students as well as their own professional productivity (inclusive of teaching, research, and service). Learning as much as we can about how faculty persons actually learn to teach online and experience online teaching can provide additional perspectives that can inform how faculty development programs should adjust to achieve their ends.

When the different types or content of faculty development offerings are tracked over time, it becomes evident that the focus has shifted from learning about a new tool or approach to focusing on pedagogy as well as instructional design options [19]. Instructional design helps faculty understand the various pedagogies that can be used to help students learn, and different ways of using different technologies to implement these pedagogies. Evans [28] is a good example of an early view of what faculty needed to teach with technology: Just tell them "how the available technology works" and "how to apply the technology" [28, p. 6] and that was all they needed to teach well with technology. However, faculty recognize that the challenge of online learning demands more and have expressed interest in learning more about pedagogical techniques for online learning [35, 36, 37]. 


\section{B. Faculty Development Models for Online Teaching}

The literature contains many articles about specific faculty development programs at specific universities. For example, the University of Central Florida requires all faculty who teach online to participate in a 70hour faculty development course; Central Michigan University also implemented professional development for online faculty that went beyond the one-time workshop to include weekly tips, online mentoring, and online teaching resources. The University of Houston system created the CampusNet Online Workshop program that includes faculty networking, hands-on practice, and a comfortable environment for asking questions of all kinds [38]. The University of Colorado created a Web Camp, offered over the summer and winter months, where faculty participate in a week-long intensive workshop that also includes hands-on training and design [36]. Michigan State University used master's students enrolled in an instructional design course to help faculty design an online course [22]. The Open University tackled development of its faculty for mobile learning by providing events, communities, exploratory spaces, and resources [39]. PBS Teacherline [40] has extensive faculty development opportunities based on problem-based approaches [41]. Capella University [42] uses a META model (for Mentoring, Engagement, Technology, and Assessment) for its faculty development for online teaching. The University of Cincinnati funded grants that were proposed by faculty or departments [43]. Colorado State University used active mastery learning, using Bloom's taxonomy and systems theory to create faculty development for online courses [44]. Fetters and Duby [45] described a faculty development program at Babson College which tied Rogers' [46] theory of innovation diffusion to blended learning. Florida Atlantic University [47] developed a detailed plan for a new central elearning unit. A community of practice approach [48] pulled nursing faculty together across multiple campuses for faculty development. A three-tiered approach was used for online faculty development, from orientation, to mentoring, and ongoing support [49]. Finally, a three-week training session at University of WisconsinLa Crosse was described in [50]. The point of reviewing these different programs is to make clear that many institutions, perhaps nearly all of them, have implemented a variety of faculty development programs aimed at helping faculty design and teach online courses in addition to using technology wisely in a traditional classroom. However, it is hard to compare the programs or assess what parts of these programs may be working well.

What is disconcerting is the lack of stringent evaluations of some (although not all) of these programs. Evaluations can help developers at other institutions decide which interventions work best based on particular outcome measures that support the conclusions. And while many of these programs may have been based on assumed theoretical frameworks, these are not clear in the articles. Perhaps these faculty developers were basing their choice of activities on adult learning theory but did not make this clear in the published material. In all fairness to these institutions and their hard-working faculty development staff, collecting detailed evaluations may not have been of immediate concern since they were likely experiencing pressures to get something underway and respond quickly to a felt need. However, to build expertise and understanding of what specific activities work and why, the field of faculty development may need to contemplate a number of changes to what they are currently doing.

\section{METHODOLOGY}

\section{A. Scholarship of Integration}

Eugene Rice [52] began the reexamination of the types of research conducted by faculty and proposed new terms to describe these types of scholarship. Subsequently, Ernest Boyer, then President of the Carnegie Foundation for the Advancement of Teaching, published Scholarship Reconsidered [52] and popularized Rice's terms for four different kinds of scholarship. Up until this time, the definition of scholarship was primarily limited to what Rice and Boyer called the "scholarship of discovery," or the unique discovery of primarily new knowledge (but which can also include confirmatory knowledge) from 
the lab or human subjects. To help broaden higher education's view of scholarship in its research and service activities, Rice and Boyer proposed three additional types of scholarship: integration, application, and teaching. Higher education responded by accepting Boyer's expanded definitions, and many institutions revised tenure and promotion guidelines to expand the types of scholarship accepted by and acceptable to faculty tenure and promotion committees.

The second scholarship, integration, focuses on making connections across disciplines and across research methodologies and interpreting this literature for possible future research studies. Integration draws insights from a broader set of publications and research studies, and depends upon a thorough and wideranging review of the research literature, including the theoretical literature, and especially multiple theories that may be relevant to the field. It "pulls disparate views and information together in creative ways" and requires scholars who can "synthesize ... look for new relationships between the parts and the whole ... relate the past and future to the present" [52, p. 13]. While a simple review of literature might be narrowly construed to prepare the groundwork for a single study and/or a set of hypotheses, this type of integration is more broad and can well provide the foundation for a new line of research. The effort described in this article is a review of the literature in the tradition of the scholarship of integration.

\section{B. Sample}

To locate the articles included in this review, a number of database searches were conducted in WilsonWeb, ExpandedAcademic, and JSTOR using such search terms as "faculty development" and "faculty development online." To look for faculty development articles specifically for online teaching, scholar.google.com was also searched, which tends to identify more articles in online journals that do not yet appear in mainstream databases. Articles were found in a large number of journals (see Appendix A), which demonstrates the difficulty of finding appropriate research articles since they seem to appear in a range of journals on higher education, faculty, online education, adult education, and separate disciplines or professions; limiting the search to a few journals would have provided a limited view of the range and diversity of these types of articles.

Articles based on formal evaluations or research methodologies were preferred and opinion articles eliminated. No distinction was made in favor of evaluations or research studies; both were included in the review and will be treated as nearly equivalent for our purposes of understanding and critiquing the current faculty development literature.

As articles were reviewed, references to prior research or theoretical literature were located, copied, and included in the analysis. The final set of articles included a total of 68 research articles and five books. Only those manuscripts which are referred to in this article are included in the list of references.

\section{Analysis}

The analytical process followed in this review of literature followed the over-100 guidelines from a popular guide to preparing literature reviews [53]. To summarize these guidelines, all articles were read carefully and salient elements of each study were identified (e.g., theoretical bases, training aims, content of training, nature of sample (number and type of participants), outcome measures). The emphasis was not on analysis of the findings of the studies or recommendations of the authors, but on the methods of arriving at the findings. Then, each article was reread and notes taken to identify each element and then how each element was differentiated, such as different theories used, different aims of training, different content of training, different sample types, or different outcome measures. It was also important to note where an article seemed to have contributed something unique to the literature or had achieved a level of research worth commending. Of course, it was also important to evaluate this material in light of guides to quantitative and qualitative research design $[54,55]$, including specification of (as appropriate to the methodology) research questions, variable definition, development of the evaluation instrument and validation, data collection, and analysis. 
This analysis produced both similarities and dissimilarities across the studies as well as significant holes or missing elements. The results of this analysis are presented as findings across studies from various disciplines and in light of standards of research design $[54,55]$.

\section{FINDINGS}

\section{A. Importance of Theory}

In Creswell's Research Design [54], theory has a critical role in both quantitative and qualitative methodologies, albeit very different roles. In quantitative research, theory is used deductively, as a way to conceptualize a study, derive testable hypotheses, and confirm (or disconfirm) the validity of the theory in the current case under study. In qualitative research, theory is used more inductively, after data are collected, or it can be developed to explain the data or more simply to explain the data that have been uncovered. In both cases, theory can be used to connect "new knowledge . . . to the vast body of knowledge to which it is relevant . . . without theory, we cannot have conceptual direction" [56, $\llbracket 1]$ or conceptual clarity where theory clarifies relationships and impacts. Theory, in other words, is a lens to view what may be disconnected bits of experience or data so that a relatively more coherent view of phenomena can be ascertained. Theory is an abstraction of more concrete experience, allowing individuals to see what might not be evident when immersed in daily experience.

In quantitative research, a theory is "an interrelated set of constructs (or variables) formed into propositions or hypotheses that specify the relationship among variables" [54, p. 82] and thus it dictates the variables (their number, specificity, and relationships among them) to be collected and tested in the study. Theories come in many different forms, as micro-level, meso-level, and macro-level [57]; as grand theories that explain large categories of phenomena, middle-range theories (which fall between minor hypotheses and grand theories), and substantive theories that are restricted to a particular setting, group, time, population, or problem [58]; and as if-then statements or hypotheses, or visual models (especially helpful in clarifying the relationships among many variables and critical to testing causal or directional models). Given the deductive nature of quantitative research, a theory precedes all specifications of hypotheses, data collection approaches, and analysis.

In qualitative research, a new theory may be proposed to explain relationships found in the data as in grounded theory research or an existing theory can be used to explain what has been found. In this latter case, patterns may be uncovered among the data collected that may emerge as a function of data analysis; patterns may interconnect in whole or only in some parts and may provide a basis for support of a preexisting theory or lay the groundwork for a new or modified theory. However, a perfect fit between prior existing theories and results derived from qualitative research may not occur; this is not considered a flaw or a test as it would be in quantitative research, but an opportunity to see the theory differently or modify its propositions to fit the data. Given the inductive process of qualitative research, a theory is more likely to appear near the end of a qualitative study as interpretation or as a final, cohesive theory (as in grounded theory).

Research into faculty development has benefited from the use of several theories, from adult learning theory to transformative learning theory, but other theories may also be useful to future faculty developers.

\section{Adult Learning Theory}

Adult learning theories were first developed by Knowles [59], who proposed the use of the term "andragogy" (rather than pedagogy) for the ways that adults learn; later, Knowles recognized that both children and adults can and do learn using teacher-directed or learner-directed approaches and redefined andragogy to be determined by the learning situation rather than the age of the learner [60]. Andragogy emphasizes the importance to adults of pursuing learning that is important to them (such as professional 
development or learning to satisfy a personal interest), something they are motivated to learn, based on their prior experiences and immediate usefulness, and is self-directed.

For example, a faculty bootcamp was designed and based on andragogy principles [61]; adult learning theories (including self-directed learning) were the basis of [62]; and adult learning principles were critical for the redesign of a faculty development program [63]. In a review of the research literature on faculty development, McQuiggan [64] found evidence that studies of faculty development had been undertaken within an "adult education" or adult learning framework.

Self-directed learning has been investigated for online learning, applied to civil servants in Taiwan [65] and casino workers [66], as well as other populations, including students, faculty, and librarians [67]. Self-directed learning became especially interesting to researchers with the advent of the Internet and its perceived usefulness for satisfying an individual's need for learning about many topics [68, 66]. In fact, as an individual's online skills improve, he or she is more likely to engage in self-directed learning [67]. For librarians, a self-directed technology training program resulted in individuals more motivated to continue their learning and more likely to incorporate new technology into their home or work duties [67]. Online instructors at community colleges were asked about their attitudes toward self-directed learning to predict their use of Web 2.0 technologies [69]; these attitudes are important in light of Web 2.0 tools that can liberate the individual to create new knowledge and take control of their learning process [70].

Self-directed learning has also been proposed as a foundation of transformative learning (see next section) by Cranton [71], so the practice (self-directed learning) and the theory (transformative learning) appear to be connected or may overlap, working to encourage change in participants. Merriam [60] posits that transformation learning is a second goal of self-directed learning, further connecting the two approaches. For example, Piling-Cormick [72] specifically proposed that transformative learning can and does occur in self-directed learning. This implies that these two theories can and do work together to create learning in adults.

\section{Transformative Learning Theory}

Transformative learning [73] is the process that changes an adult's perspective. Mezirow [74, p. 5] proposed that "Adults have acquired a coherent body of experience - associations, concepts, values, feelings, conditioned responses - frames of reference that define their life worlds . . They selectively shape and delimit expectations, perceptions, cognition, and feelings . . . we have a strong tendency to reject ideas that fail to fit our preconceptions." Adults naturally seek evidence as they learn that their views are correct, or they can establish new views, or transform those view(s) to something else. Perspective transformation is accomplished through the disorienting dilemma - an experience that forces the individual to question prior beliefs - and through autonomous thinking which involves serious reflection on one's beliefs and assumptions, discussion of new information, and empathy toward other perspectives. Reflection is not a simple process, but includes three levels of content, process, and premise. Content reflection examines the content or description of the problem; process reflection examines the problem-solving strategies used; and premise reflection is the key to a transformation of meaning [75]. Reflection can further be applied to one's emotions, the efficacy of one's perceptions, thoughts, and actions, and one's judgments, concepts, and theories that result from poor or limited information [75]. All of these reflection types create a critical reflection model of learning, which might be especially helpful to faculty developers trying to change a faculty member's perspectives about teaching online, student learning, or their role as instructor.

It is not surprising that, given this definition of transformative learning, several evaluations and research studies conducted on faculty development programs are based on this theory. McQuiggan [76] is an excellent example of an action research study based on reflection journals and interviews with participants after an extensive faculty development experience including planning, face-to-face sessions, and web conferencing. By including activities specifically intended to encourage reflection on core 
teaching beliefs, participants examined their reliance on lecturing, revised assignments to emphasize student construction of knowledge, and changed their teaching practices in face-to-face classes.

Critical reflection was found to be important in the perspective transformation of $62 \%$ of the faculty involved in faculty development [77], where participants developed more open-minded attitudes towards others, became more appreciative of multiple perspectives, and developed stronger reflective practices applied to their work. In a study of teacher educators undergoing training in educational technologies, participants changed their views of the teaching profession as well as what constitutes good educational practice [78], a finding that is consistent with transformational learning theory. Hubball, Collins, and Pratt [79] incorporated critical reflective practice (based on Schön's [80] work of the same name) into an 8month certificate program for faculty at the University of British Columbia; using the Teaching Perspectives Inventory, scores for those participating in the program increased significantly on all of the measures. McQuiggan [64], in an earlier review of the faculty development literature, found evidence that faculty development efforts were helping faculty transform their views of teaching. Early experiences while teaching online were bewildering, overwhelming, and disempowering for faculty, but reflection and assessment of their prior beliefs about what constitutes good teaching led participants to change their views of their role in the online course. McQuiggan [64] asserts, however, that faculty development that focuses primarily on teaching technology skills will not necessarily lead to challenging prior attitudes; she argues that faculty development needs to do both. For institutions and faculty developers deeply committed to helping faculty transform their views of what good teaching is, basing faculty development for online teaching on transformational learning theory may be an excellent choice.

\section{Other Theories}

While the majority of faculty development articles that include a reference to theory use adult learning or transformative learning theory, other theories have been suggested although not yet included in studies. Trotter [81] has recommended "age and stage" theories such as the theory of ego development where adults move from conformity to independence and then reconciliation with conflicts [82]; Kohlberg's [83] theory of moral development which includes the individual's orientation to authority and others across the life cycle; and Kegan's [84] theory of individual development from self-centered to other-centered to a more balanced view of self and other. Perry [85] proposed a cognitive development theory tracking development from dualism to commitment to relativism, and Gibb [86] developed a functional theory of adult learning that stresses the importance of learning that is problem or experience based. Perhaps multiple intelligences theory [87] can contribute to research on faculty development (as urged by [88]) or application of learning styles (e.g., auditory, visual, kinesthetic). These are necessarily incomplete descriptions of these theories, and the interested reader is encouraged to investigate the authors further to better understand how these theories might affect the delivery and success of faculty development activities.

It may be useful to apply some learning theories and concepts researched in regards to student learning to the faculty development process. We know that experiential learning [89] is a powerful approach for learners to discover new meaning and that this is consistent with adult learning theory given its emphasis on building upon adults' experiences [90]. Experiential learning also has the advantage of providing superior retention of learning rates (as high as 75\%, compared to lecture which is 5\%) [90, Figure 1]. Connectivism [91] is another theory not yet applied to faculty learning, but which integrates ideas from chaos, network, complexity, and self-organization theories and relies on seeking multiple information sources (including the Internet) and developing the ability to see connections between fields, ideas, and concepts. Phelps [92] investigated the use of complexity theory which is non-linear, stresses meaning in context, and uncertainty in causality; this is seen as a more representative learning theory since real life is not ordered or logically structured. The social constructivist theory of learning was applied to understanding the professional development of traditional lecturers adjusting to the online mode of learning [93]. Although never applied (so far) to faculty development conducted in an online setting, 
perhaps the Community of Inquiry model [94] may provide intriguing insights into how faculty persons learn in an online class by understanding cognitive, teaching, and social presence in the online course they are learning in and the online course they are teaching. In any case a wealth of learning theories - in addition to the valuable theories of adult learning and transformational learning - may be usefully applied to understanding how faculty learn to teach online.

Another construct that might be especially worthwhile for faculty development for online teaching is TPCK: Technological Pedagogical Content Knowledge [95]. Teaching online is characterized as needing all three - content, pedagogy, and technical knowledge - but also as a complex web of relationships between and among the single topics. For instance, pedagogical content knowledge is the knowledge of pedagogy that is applicable to teaching specific content, technological content knowledge is the understanding of how technology and content relate to each other, and technological pedagogical knowledge emphasizes how different technologies can be used in teaching [95, p. 743]. TPCK brings together these separate and relating concepts to produce online learning that is founded on the best understanding of how technology, pedagogy, and content combine to create learning. While this construct may not be a theory in the sense of the learning theories above, it may provide a structure that helps faculty see what they do online in multiple frames and to recognize the importance of trying to design activities that make the best use of technology and the best choice of pedagogy for the learning objective or content of the unit or course. In this sense, TPCK is an integrative theory of online coursework that recognizes the complexity of good online instruction.

\section{Use of Theory in Faculty Development Research}

It is important to stress that the articles reviewed which were based on or referred to a theory were few in number, totaling only $15 \%$ of the articles reviewed. This should not be construed as meaning that faculty developers were unaware of theories; perhaps their choices were based unconsciously on theories of learning. The main point to be made is that a theoretical underpinning was not made clear in the article. If faculty development providers and evaluators wish to establish their practice and changes to those practices on more solid footing, more research that is based on theory (or seeks to establish new theory as is possible in qualitative research) is required. This is a serious flaw in faculty development articles, and could easily be remedied with use of existing theories such as transformative learning, which seems particularly apt for faculty developers wishing to change how faculty members understand their teaching role, or the development of new or revised theory that is appropriate for this population and the online teaching situation.

\section{B. Models for Practitioners}

The emphasis on the need for theory above should not be construed to mean that the many articles describing different institutional models in an earlier section have no value. It is sufficient to say that faculty developers have been creative in their designs and models and often wish to share these with others in the field. Other developers, either new to the field or needing new ideas to stimulate their own practice, can find good ideas among such articles and - more importantly - further improve upon their own or other's ideas in ways that ought to be shared with the professional community of faculty developers. However, to make progress in understanding what works and why, theory is likely needed. And to lift the model above its one-institution norm, models - or pieces of models - need to be replicated across institutions and careful analyses conducted.

Another suggestion for improving the discussion of models is to arrive at some consistency when describing pieces of models. A seminar in one model is a workshop in another and workshops can be distinguished by their length, but are there important differences in a one-hour workshop versus a threehour workshop? While the variety of models can be seen as a strength within the faculty development community, the Babel of terms and approaches works against producing insights or research results that can be easily understood and transferred from one development enterprise to another. Perhaps arriving at 
common definitions or descriptions can help move the discussion and research on faculty development models into more rigorous and consistent findings.

\section{Disentangling Treatments}

As referred to in an earlier section, it is intriguing how many faculty development efforts are not one thing at all: they are several activities, structured in many ways, taking an afternoon or a week or a summer. How can evaluations unravel all of these treatments so that faculty developers can know which treatment is best for this faculty member or for that cost? This is especially critical as institutional and program budgets are cut or constrained, since faculty developers may increasingly be asked to produce more or better results with the same or lower budget, and thus faculty development professionals must ask which activities to keep and which may need to be dropped. To make this critical decision, faculty developers will need to ask how each element of the faculty development effort contributes to the changes it wants; for example, it will need to break down the effectiveness of specific parts of the workshop - the introductions, the collaborations, the one-on-one consulting, the group discussions, the pedagogies used to teach new pedagogies, the technologies used to teach new technologies, and so forth - so that specific information is available.

King [76] attempted to disentangle the influences on faculty by asking them questions about what activities influenced their perspective transformation: $86.1 \%$ of participants mentioned learning activities, which is further broken down into discussion (69.4\% of participants), journals (52.8\%), reflection $(47.2 \%)$ and readings $(47.2 \%)$. A total of $72 \%$ of participants also mentioned the influence of other persons, including a professor $(33 \%)$, classmate $(28 \%)$ or other student $(28 \%)$. This is a useful attempt to begin disentangling the activities and influences going on in faculty development efforts.

This is enormously difficult to do and will require a different approach to evaluation, perhaps exploring just-in-time evaluation (an evaluation screen that pops up at the completion of an activity), or reflective evaluations (asking participants to identify what activity helped them to learn or understand a concept), or authentic assessments (asking participants - or program completers - to produce an example of the learning intended). This may go well beyond what is usually conducted under the name of formative and summative evaluations, and may include multiple formative evaluations (to capture learning that is the result of a specific activity) as well as longer-term evaluations (to capture the learning that may take time to sink in). The goal of such efforts of disentangling the effects of a variety of treatments is to understand - precisely - what is working and for whom and conversely, what is not working and for whom.

\section{Rigorous Evaluations}

Kucsera and Svinicki [96] conducted a literature review of nine journals that published faculty development evaluations between 1992 and 2007. Unfortunately, they concluded that only a few studies "met best practice standards" [96, p. 5] for program evaluations or for precision in those evaluations. To put this insight into perspective, only $47 \%$ of the articles included in this review could be construed as "research" (defined broadly as both quantitative and qualitative and including any outcome measures at all). The lack of good program evaluations is because faculty development programs are complex (comprising many parts and activities as noted above), take place over an extended period of time, and comprise small samples of faculty who are evaluated immediately at the end of the training, rather than being followed over time. While randomization and other qualities of good evaluation may never be possible given the constrained budgets of faculty development programs, the authors conclude that perhaps qualitative research methods - such as ethnographies, anthropological methods, and case studies $[96$, p. 8] - would be more likely to lead to useful insights into the training provided to faculty.

Evaluations of faculty development programs or trainings have increasingly depended on qualitative research methods (as recommended by [96] above) and eschewed the identification of outcome measures a priori. For example, Lackey [97] interviewed six participants in faculty development for teaching online and found that one-on-one assistance as well as both technical and pedagogical training were most 
beneficial to preparing them to teach online. While an example of good qualitative research, more studies like this one and McQuiggan's [76] are needed as well as larger studies.

Both in addition to evaluating a particular faculty development activity, the literature so far lacks rigorous research comparing the effects of different faculty development models, programs, or activities, or comparing these across different institutions. It is understandable why this has not been done, since it would be costly to conduct and gather such cross-institutional data and no current source of funding for such research is available. However, perhaps individual faculty developers can pool resources across institutions to undertake such an endeavor in the future.

\section{E. Faculty Differences}

One of the very curious absences in this review of the literature was the lack of attention to individual learner differences in the evaluations of faculty development programs. Why might this be so? Do developers and those who design and carry out evaluations believe that faculty members learn in a homogenous fashion? Do faculty think, act, and believe as a single entity?

Currently, much of faculty development is packaged as a "one-size-fits-all" endeavor; yes, there are courses, and workshops, and one-on-one assistance. But perhaps all of these forms only reveal the same assumptions about how faculty persons think, feel, and learn. Faculty do need to learn new skills, but perhaps the ways they learn are more diverse than our current faculty development models account for.

Certainly, individual differences are explored by some authors, especially Grant [24] who looked at intrinsic and extrinsic factors that influenced faculty satisfaction with training on a course management system. Edwards [9] found that faculty persons who saw their role as guides to learning were more likely to complete all of the faculty development modules than faculty who saw their role as providers of content. Findings such as these help us better understand whether faculty will benefit from a development experience and whether developers ought to provide multiple training types for different types of faculty learners.

We need studies that delve into the faculty's different perceptions of their role, student learning, and appropriate pedagogy for their discipline. We also need to better understand the faculty person's learning styles and preferences, as well as differences by other kinds of personal and professional variables.

\section{F. Outcome Measures}

What kinds of outcome measures did these studies use to base their assessment of the faculty development effort? This question has a disquieting answer: not many are named, and the few that are mentioned are not particularly clear or robust. Here is a partial list: number of new educational programs added [12], opinions about effectiveness of the training [98], adoption of case studies in instruction [20], improved teaching [10], professional growth of faculty [8], usefulness [7], satisfaction or relevance to participant [11], use of portfolios [19], more cooperation across disciplines [43], and confidence with and attitudes about assessment [16]. [11] compiled a variety of outcome measures used in faculty development effort for medical educators, from a positive change in attitudes to increased knowledge of and change in teaching behavior or student learning. [40] included such outcome measures of the faculty development provided to PBS online teachers as a score on the course rubric, learner course grades, and turnover of faculty. Edwards [9] also identified possible moderating variables: faculty who think of themselves as facilitators of learning (rather than disseminator of information) or had a higher sense of personal efficacy were more successful in completing all of the faculty development modules; also, knowledge of pedagogy and innovative course design were also important for successful change. Koepke [50] found that training changed faculty's conceptions or "myths" of online learning, away from more critical or negative points of view as well as changed several teaching behaviors: from adding video and audio files to providing more, and more prompt, feedback. Orozco et al. [47] found that faculty development yielded such outcomes as increased comfort with using technology but also 27 detailed evaluations of the training provided (from "objective clarity" to "ease of interaction" to "discussion effectiveness"). What is clear from this list is that some do a better job of delineating outcomes of interest 
and either developing an evaluation instrument to measure those or delving more deeply into the factors that lead to faculty change $[9,16]$, and others are too amorphous or poorly defined to be identified with any confidence.

Outcome measures for faculty development for online teaching include usefulness (as assessed by the participant), willingness to recommend the training to another faculty, self-reported knowledge or ratings of self-efficacy, changes in behavior, beliefs, and attitudes [23]. Schrum et al. [29] included many of these measures, but also self-reports of participants' altering their pedagogy, redesigning their courses, or experiencing community online. In an attempt to understand the reasons for satisfaction with faculty development, Grant [24] investigated an individual's intrinsic factors (convenience, comfort, interests) and extrinsic factor (external pressure to teach online). In a more detailed evaluation of Purdue University at Calumet's online courses for faculty, 47 participants underwent a year-long development program and then were followed over four years; the program evaluation included 72 evaluation items, from "I am satisfied" to "My on-campus teaching has improved" [99]. Potter and Meisels [27] included such authentic measurements as giving an example of how the faculty development impacted the individual's "ability to think critically and use information to solve problems and answer questions," "understanding of science in the news," and applications of "problem-solving approaches learned" in the training (p. 194). These examples are then enhanced with further reflective questions that focus faculty persons' attention on their teaching beliefs and application of concepts to other courses taught.

What is clear from this information is that outcome measures are often poorly defined or poorly measured, depending on the honesty and self-understanding of those undergoing the training. While many faculty possess these qualities, evaluations of faculty development should not depend solely on such measures and should attempt to develop new ways to identify authentic outcomes of the training. Although authentic assessments are often more cumbersome and more costly than simple Likert-scale items, perhaps they are a way to give flesh to the bones of our current set of outcome measures.

\section{G. Cost-Effectiveness of Faculty Development}

Another intriguing hole in the literature is the lack of consideration of cost-effectiveness of faculty development offerings. Certainly, this would be a difficult undertaking, but as institutional budgets are becoming more constrained by a decline in state funding, increased competition among internal parts of an institution for institutional resources, and increased demands on institutions for services as well as accountability, assessing cost-effectiveness of faculty development becomes more essential. How can faculty developers justify their activities if they cannot provide a good estimate of a) the cost of each effort, b) the efficiency of that effort (defined by the number of outcomes produced for the cost or costefficiency), and c) the quality of those outcomes for the cost (defined as cost-effectiveness)? Of course, undertaking such a calculation involves several of the above issues: a better understanding of the outcomes produced by faculty development efforts as well as a way to evaluate all aspects of faculty development efforts. With better attention to these elements, faculty developers may one day be able to say that while a workshop costs less to provide, one-on-one consulting provides more pertinent changes to online courses. Or that efforts that emphasize transformative learning and take time to conduct may change a participant's philosophy of teaching and therefore be very costly, but may have secondary and tertiary outcomes in courses taught by the faculty person compared to a workshop on preparing a podcast, wiki, or blog. While the latter may still be essential, perhaps less costly ways of providing these skills can be explored. In any case, the final result would be faculty developers empowered with the data and the insights into their enterprise to make the best choices for the outcomes desired and the budget available to them.

\section{RECOMMENDATIONS}

The analysis of the literature so far has found seven problematic qualities that lead to seven 
recommendations for consideration by faculty developers as well as those who conduct research in this area.

First, the lack of a theory base for design of the training is problematic and discourages progress in our understanding of why or how faculty development can be improved. This should not be construed to mean that the designers of the training did not have a learning theory in mind when designing the training, but such theory is not clearly indicated in some of the articles based on the training. This is a potential hole in our understanding of faculty development and is an uncertain base that may preclude professionalizing faculty development practice. Without theory or theories, faculty development will likely stay an auxiliary function in higher education when it could be an essential foundation to helping faculty learn the skills they need to be vital and productive members of the academy as well as helping institutions chart a course through the changes that are happening to higher education now and in the future.

Second, articles will likely continue to be published that profile a certain institution's faculty development program simply because such articles are a means for faculty developers to share what they are doing and any new developments or activities (or combinations of activities) with others in the field. There is a valuable role for this function in the literature, but let us recognize that these publications do not necessarily advance the field and our understanding of what works and why.

Third, research needs to be undertaken that disentangles the various treatments included in faculty development programs. Rather than evaluate the program as a whole, we must attempt to assess the usefulness of separate activities, each (hopefully) with a theoretical basis for inclusion in the program. Because many current articles tend to evaluate a set of treatments or a model, it is impossible to evaluate the worth of these treatments from these articles or know which individual action or activity might work best for the individual faculty experiencing the activity. By disentangling a myriad of treatments and understanding the role and impact of each one separately, faculty developers will have made progress toward tailoring training for faculty that is matched to that faculty person's learning needs.

Fourth, research is needed that is rigorous, possessing the aspects of quality research or high-quality evaluation. This would require familiarity with such evaluation guides as [100] and the will and resources to do evaluation well. It would also require the willing participation of faculty, whose time is at a premium. Also, to move evaluations to a more rigorous level will mean that evaluations based on one institution or one model of training must be made more precise (see next recommendation) or include more comparisons to other faculty development activities, programs, or institutions. Research on only one program may produce idiosyncratic results (that is, results peculiar to that institution) that may or may not be generalizable to other institutions.

This last point is integrally tied to the fifth recommendation, to develop outcome measures that are more than "satisfaction" with the training or an assessment of the training's usefulness in the participant's opinion. Fortunately, several articles above have proposed outcome measures that focus on the impact of the training on faculty and on their face-to-face courses, on student learning, and on the institution as a whole. This is an open area which requires additional work to be done, not only to incorporate the outcomes proposed by various theories, but also to keep our eyes out for unintended consequences of our efforts. One unintended consequence that seems possible is the replacement of "one best" teaching method with another "best" method, which reinforces an individual's expectation that one solution will solve a variety of teaching problems, rather than learning how to design coursework that is flexible and fitting for many types of students.

The final two recommendations which follow address two sizable "holes" in the research literature identified above. Sixth, articles published in the journals rarely include variables or constructs that capture individual faculty learning differences, or account for why such differences might affect the outcomes (in this way, the literature on faculty development seems to be behind the literature on student learning). Seventh, only a very few articles discuss the cost of the training and none assess the training in terms of a cost-benefit analysis. As higher education continues to feel the constraints of declining state 
funding and rising costs, assessing the cost of faculty development training programs is essential. Cost analyses are a demanding endeavor - requiring time, money, and wisdom to do well -- but they are necessary to understand the cost-effectiveness or -efficiency of this training in terms of the outcomes the training is intended to achieve.

These findings tend to support several new directions for research on faculty development of online teaching that combine or cross these seven recommendations. First, we need to coordinate our efforts, which may be a useful function of the Sloan Consortium and other bodies of active faculty developers. We need studies that include several institutions or different institutional types, disciplines, faculty types, and outcomes. This can be done when several faculty developers at different institutions choose to work together to test similar approaches, develop and share outcomes measures, and share materials developed at one institution but shared with many. One can see a time when multiple institutions, working together, develop multiple tests, evaluation tools, or online modules that can then be shared among the institutions, thereby saving the development cost of doing all of these functions separately.

Second, we need to adopt one or several theoretical constructs for these studies, from adult learning theory, to transformational learning, to TCPK mentioned earlier; these are not an exhaustive set of useful learning theories that may apply to faculty. We need comparisons of theory-based approaches to determine if some theories seem more viable for this function than others or if different theories work for different learning outcomes. Third, we need to draw upon the literature on individual differences in adult learning so that these can be incorporated into research on faculty development, from learning styles to Myers-Briggs Types to other approaches that illuminate how an individual might respond to online teaching or various faculty development approaches in a unique manner.

Fourth, we may need to work with educational researchers to design ways to test small, discrete events in the training so that these can be assessed for their value. Fifth, researchers in faculty development may wish to discuss and adopt some common definitions of training approaches and outcome measures so that results can more easily be compared across studies. All of these suggestions require some concerted action and such coordination may lift the faculty development field from one of active practice and exploration to solid, research-based foundations that have been tested and proven across many campuses.

In other words, based on this analysis of the research and theoretical literature applied to faculty development for online teaching, I wish to argue that the research on faculty development for online teaching needs to be improved along the lines indicated above so that its findings can more reliably and helpfully inform future practice among institutions wishing to help faculty improve their online teaching. The future of higher education depends upon vibrant, active, and knowledgeable faculty members who are continuously improving their online teaching skills and helping our students learn well in our online courses and programs. Faculty developers are critical to encouraging and supporting these changes among the faculty who teach online.

\title{
VI. ACKNOWLEDGEMENTS
}

Deleted for Review

\section{ABOUT THE AUTHOR}

Deleted for Review

\author{
VIII.REFERENCES
}


An Analysis of the Research on Faculty Development for Online Teaching and Identification of New

Directions

1. Sloan Consortium. Quality framework narrative, the 5 pillars. http://sloanconsortium.org/Quality Framework Narrative 5 pillars.

2. Sorcinelli, M., Austin, A., Eddy, P., \& Beach, A. Creating the future of faculty development: Learning from the past, understanding the present. Bolton, MA: Anker Publishing, 2006.

3. Gillespie, K.J., \& Robertson, D.L. A Guide to Faculty Development ( $2^{\text {nd }}$ edition). San Francisco, CA: Jossey-Bass, 2010.

4. Cook, C., Kaplan, M., \& Monts, L.P. Advancing the Culture of Teaching on Campus. Sterling, VA: Stylus, 2011.

5. Schroeder, C. Coming in from the margins. Sterling, VA: Stylus, 2010.

6. Major, C.H., \& Palmer, B. Reshaping teaching and learning: The transformation of faculty pedagogical content knowledge. Higher Education, 51(4): 619-647, 2006.

7. Lindman, J.M., \& Tahamont, M. Transforming selves, transforming courses: Faculty and staff development and the construction of interdisciplinary diversity courses. Innovative Higher Education, 39(4): 289-304, 2006.

8. DiLorenzo, T.M., \& Heppner, P.P. The role of an academic department in promoting faculty development: Recognizing diversity and leading to excellence. Journal of Counseling \& Development, 72(5): 485-491, 1994.

9. Edwards, L., Freeman, L.M., Hodges, J., Johnston, R.A., Odell, M., \& Sunal, C.S. Teaching science in higher education. School Science and Mathematics, 101(5): 246-257, 2001.

10. Atheny, S., \& Hoffman, K.D. The Master Teacher Initiative: A framework for faculty development. Marketing Education Review, 17(3): 1-9, 2007.

11. Steinert, Y., Mann, K., Centeno, A., Dolmans, D., Spencer, J., Gelula, M., \& Prideaux, D. A systematic review of faculty development initiatives designed to improve teaching effectiveness in medical education. Medical Teacher, 28(6): 497-526, 2006.

12. Gruppen, L.D., Frohna, A.Z., Anderson, R.M., \& Lowe, K.D. Faculty development for educational leadership and scholarship. Academic Medicine, 78(2): 137-141, 2003.

13. Bland, C.J., \& Risbey, K.R. Faculty development programs. Effective Practices for Academic Leaders, 1(7): 1-16, 2006.

14. Murray, J. Faculty development in a national sample of community colleges. Community College Review, 27(3): 47-64, 1999.

15. Murray, J. Faculty development in publicly supported two-year colleges. Community College Journal of Research and Practice, 25(7): 487-502, 2001.

16. Haviland, D., Shin, S., \& Turley, S. Now I'm ready: The impact of a professional development initiative on faculty concerns with program assessment. Innovative Higher Education, 35(4): 261$275,2010$.

17. Watson, G., \& Grossman, L.H. Pursuing a comprehensive faculty development program: Making fragmentation work. Journal of Counseling \& Development, 72(5): 465-473, 1994.

18. Daly, C.J., \& Dee, J.R. Innovative models for organizing faculty development programs: Pedagogical reflexivity, student learning empathy, and faculty agency. Human Architecture: Journal of the Sociology of Self-Knowledge, 7(1): 1-22, 2009.

19. Lavoie, D., \& Rosman, A.J. Using active student-centered learning-based instructional design to develop faculty and improve course design, delivery, and evaluation. Issues in Accounting Education, 22(1): 105-118, 2007.

20. Anurag, S., \& Brajesh, K. An approach for faculty development. Advances in Management, 2(10): 54-58, 2009.

21. Shea, T. P., Sherer, P. D., \& Kristensen, E. W. Harnessing the potential of online faculty development: Challenges and opportunities. To Improve The Academy, 20: 162-179, 2002.

22. Koehler, M.J., Mishra, P., Hershey, K., \& Peruski, L. With a little help from your students: A new model for faculty development and online course design. Journal of Technology and Teacher Education, 12(1): 25-55, 2004. 
23. Skeff, K.M., Stratos, G.A., Mygdal, W., DeWitt, T.A., Manfred, L., Quirk, M., Roberts, K., Greenberg, L., \& Bland, C.J. Faculty development. Journal of General Internal Medicine, 12: 5663, 1997.

24. Grant, M.M. Learning to teach with the web: Factors influencing teacher education faculty. Internet and Higher Education, 7:329-341, 2004.

25. Howell, S.L., Saba, F., Lindsay, N.K., \& Williams, P.B. Seven strategies for enabling faculty success in distance education. Internet and Higher Education, 7:33-49, 2004.

26. Kane, S.A. Interdisciplinary faculty development seminar: A model for learning emerging technologies while developing interdisciplinary partnerships. Journal of Science Education and Technology, 12(4): 421-430, 2003.

27. Potter, R., \& Meisels, G. Enhancing teacher preparation and improving faculty teaching skills: Lessons learned from implementing "Science That Matters" a standards based interdisciplinary science course sequence. Journal of Science Education and Technology, 14(2): 191-204, 2005.

28. Evans, J.R. The emerging role of the Internet in marketing education from traditional teaching to technology-based education. Marketing Education Review, 11(3): 1014, 2001.

29. Schrum, L., Burbank, M.D., Engle, J., Chambers, J.A., \& Glassett, K.F. Post-secondary educators' professional development: Investigation of an online approach to enhancing teaching and learning. Internet and Higher Education, 8: 279-289, 2005.

30. Diaz, V. Cloud-based technologies: Faculty development, support, and implementation. Journal of Asynchronous Learning Networks, 15(1): 95-102, 2011.

31. Palloff, R.M., \& Pratt, K. Building learning communities in cyberspace: Effective strategies for the online classroom. San Francisco: Jossey-Bass, 1999.

32. Conceição, S.C.O. Faculty lived experiences in the online environment. Adult Education Quarterly, 57(1): 26-45, 2006.

33. Major, C.H. Do virtual professors dream of electric students? University faculty experiences with online distance education. Teachers College Record, 112(8), 2154-2208, 2010.

34. Meyer, K.A. The influence of online teaching on faculty productivity. Innovative Higher Education, 37(1), 37-52, 2012.

35. Hinson, J. M., \& LaPrairie, K. N. Learning to teach online: Promoting success through professional development. Community College Journal of Research and Practice, 29, 483-493, 2005.

36. Lowenthal, P.R., \& Thomas, D. Digital campfires: Innovations in helping faculty explore the online learning wilderness. MERLOT Journal of Online Learning and Teaching, 6(3), 2010. http://jolt.merlot.org/vol6no3/lowenthal 0910.htm

37. Pankowski, P. Faculty Training. T.H.E. Journal. September 2004.

38. Kidney, G.W., \& Frieden, S. When the cows come home: A proven path of professional development for faculty pursuing e-learning. The Journal, 2004. http://thejournal.com/Articles/2004/06/01/When-the-Cows-Come-Home-A-Proven-Path-of Professional-Development-for-Faculty-Pursuing-ELearning.aspx

39. Kukulska-Hulme, A. How should the higher education workforce adapt to advancements in technology for teaching and learning? Internet and Higher Education, 15(4), 247-254, 2012.

40. Storandt, B.C., Lacher, A.P., \& Dossin, L.C. Toward an understanding of what works in professional development for online instructors: The case of PBS Teacherline. Journal of Asynchronous Learning Networks, 12(1): 121-162, 2012.

41. Southern Regional Education Board (SREB). Guidelines for professional development for online teachers. Southern Regional Education Board: Atlanta, GA, 2009. http://publications.sreb.org/2009/09T01_Guide_profdev_online teach.pdf

42. Dittmar, E., \& McCracken, H. Promoting continuous quality improvement in online education: The META model. Journal of Asynchronous Learning Networks, 12(1): 163-176, 2012. 
An Analysis of the Research on Faculty Development for Online Teaching and Identification of New

Directions

43. Camblin, L.D., \& Steger, J.A. Rethinking faculty development. Higher Education, 39(1):1-18, 2000.

44. Puzziferro., M., \& Shelton, K. A model for developing high-quality online courses: Integrating a systems approach with learning theory. Journal of Asynchronous Learning Networks, 12(3-4): 119136, 2008.

45. Fetters, M.L., \& Duby, T.G. Faculty development: A stage model matched to blended learning maturation. Journal of Asynchronous Learning Networks, 15(1): 77-85, 2011.

46. Rogers, E.M. Diffusion of Innovation. New York: Free Press, 2003.

47. Orozcco, M., Fowkles, J.K., Jerzak, P., \& Musgrove, A. Zero to sixty plus in 108 days: Launching a central elearning unit and its first faculty development program. Journal of Asynchronous Learning Networks, 12(1): 177-192, 2012.

48. Reilly, J., Vandenhouten, C., \& Gallagher-Lepak, S. Faculty development for e-learning: A multi-campus community of practice (COP) approach. Journal of Asynchronous Learning Networks, 12(1): 99-110, 2012.

49. Vaill, A.L., \& Testori, P.A. Orientation, mentoring and ongoing support: A three-tiered approach to online faculty development. Journal of Asynchronous Learning Networks, 12(1): 111-120, 2012.

50. Koepke, K., \& O'Brien, A. Advancing pedagogy: Evidence for the role of online instructor training in improved pedagogical practices. Journal of Asynchronous Learning Networks, 12(1): 73$84,2012$.

51. Rice, R.E. The new American scholar. Metropolitan Universities, 1(4): 7-18, 1991.

52. Boyer, E. L. Scholarship reconsidered: Priorities of the professoriate. San Francisco: Jossey-Bass, 1997.

53. Galvan, J.L. Writing Literature Reviews ( $4^{\text {th }}$ edition). Glendale, CA: Pyrczak Publishing, 2009.

54. Creswell, J.W. Research Design: Quantitative and Qualitative Approaches. Thousand Oaks, CA: Sage Publications, 2004.

55. Maxwell, J.A. Qualitative Research Design: An Interactive Approach. Thousand Oaks, CA: Sage Publications, 1996.

56. DePoy, E., \& Gitlin, L.N. Introduction to Research: Multiple Strategies for Health and Human Services ( $2^{\text {nd }}$ edition). St. Louis, MO: Mosby, 1998. Retrieved from http://www.umdnj.edu/idsweb/shared/why is theory important chpt6 depoy.htm

57. Neuman, W.L. Social research methods: Qualitative and quantitative approaches. Boston, MA: Allyn \& Bacon, 1991.

58. Merriam, S.B. Case study research in education: A qualitative approach. San Francisco: JosseyBass, 1988.

59. Knowles, M.S. Self-directed learning. New York: Association Press, 1975.

60. Merriam, S.B. Andragogy and self-directed learning: Pillars of adult learning theory. New Directions for Adult and Continuing Education, 89: 3-13, 2001.

61. Johnson, T., Wisniewski, M.A., Kuhlemeyer, G., Isaacs, G., \& Krzykowski, J. Technology adoption in higher education: Overcoming anxiety through faculty bootcamp. Journal of Asynchronous Learning Networks, 12(1): 63-72, 2012.

62. Henning, T.B. Writing professor as adult learner: An autoethnography of online professional development. Journal of Asynchronous Learning Networks, 12(1): 9-26, 2012.

63. DeNoyelles, A., Cobb, C., \& Lowe, D. Influence of reduced seat time on satisfaction and perception of course development goals: A case study in faculty development. Journal of Asynchronous Learning Networks, 12(1): 85-98, 2012.

64. McQuiggan, C.A. The role of faculty development in online teaching's potential to question teaching beliefs and assumptions. Online Journal of Distance Learning Administration, 10(3), 2007. http://www.westga.edu/ distance/ojdla/fall103/mcquiggan103.pdf

65. Lai, H. The influence of adult learners' self-directed learning readiness and network literacy on online learning effectiveness: A study of civil servants in Taiwan. Educational Technology \& Society, 14(2): 98-106, 2011. 
66. Lema, J., \& Agrusa, J. Relationship of WWW usage and employee learning in the casino industry. International Journal of Hospitality Management, 28(1): 18-25, 2009.

67. Quinney, K.L., Smith, S.D., \& Galbraith, Q. Bridging the gap: Self-directed staff technology training. Information Technology and Libraries, 29(4): 2-5-213, 2010.

68. Hiemstra, R. Is the internet changing self-directed learning? International Journal of Self-directed Learning, 3(2); 45-60, 2006.

69. Ulrich, J., \& Karvonen, M. Faculty instructional attitudes, interest, and intention: Predictors of Web 2.0 use in online courses. Internet and Higher Education, 14: 207-216, 2011.

70. Kop, R. Web 2.0 technologies: Disruptive or liberating for adult education? Adult Education Research Conference, 2008. http://www.adulterc.org/Proceedings/2008/Proceedings/Kop.pdf

71. Cranton, P. Professional Development as Transformative Learning. San Francisco: Jossey-Bass, 1996.

72. Piling-Cormick, J. Transformative and self-directed learning in practice. New Directions for Adult and Continuing Education, 74: 69-77, 1997.

73. Mezirow, J. Transformative Dimension of Adult Learning. San Francisco: Jossey-Bass, 1991.

74. Mezirow, J. Transformative learning: Theory to practice. New Directions for Adult and Continuing Education, 74: 5-12, 1997.

75. Wang, V.C.X \& King, K.P. Understanding Mezirow's theory of reflectivity from Confucian perspectives: A model and perspective. Radical Pedagogy, 8(1), 2006. http://radicalpedagogy.icaap.org/content/issue8 1/wang.html

76. McQuiggan, C.A. Faculty development for online teaching as a catalyst for change. Journal of Asynchronous Learning Networks, 12(1): 27-62, 2012.

77. King, K.P. Both sides now: Examining transformative learning and professional development of educators. Innovative Higher Education, 29(2): 155-174, 2004.

78. King, K.P. Educational technology professional development as transformative learning opportunities. Computers \& Education, 39: 283-297, 2002.

79. Hubball, H., Collins, J., \& Pratt, D. Enhancing reflective teaching practices: Implications for faculty development programs. The Canadian Journal of Higher Education, 35(3): 57-81, 2005.

80. Schön, D.A. Educating the reflective practitioner: Toward a new design for teaching and learning in the professions. San Francisco: Jossey-Bass, Inc., 1996.

81. Trotter, Y.D. Adult learning theories: Impacting professional development programs. Delta Kappa Gamma Bulletin, 72(2): 8-13, 2006.

82. Loevinger, J. Ego Development: Conceptions and Theories. San Francisco: Jossey-Bass, 1976.

83. Kohlberg, L. Stage and sequence: The cognitive development approach to socialization." In D.A. Goslin (Ed.), Handbook of Socialization Theory and Research (p. 347-380). Chicago: RandMcNally, 1969.

84. Kegan, R. The Evolving Self: Problem and Process in Human Development. Cambridge, MA: Harvard University Press, 1982

85. Perry, W.G. Forms of Intellectual and Ethical Development in the College Years. New York: Holt, Rinehart and Winston, 1970.

86. Gibb, J.R. Learning theory in adult education. In M.S. Knowles (Ed.), Handbook of Adult Education in the United States, (p. 54-64). Washington D.C.: Adult Education Association of the USA, 1960.

87. Gardner, H. Multiple intelligences: New horizons. New York: Basic Books, 2006.

88. Riha, M., \& Robles-Piña, R.A. The influence of multiple intelligence theory on web-based learning. MERLOT Journal of Online Learning and Teaching, 5(1): 97-103.

89. Kolb, D.A. Experiential Learning: Experience as the Source of Learning and Development. Englewood Cliffs, NH: Prentice-Hall, 1984. 
90. Lobel, M., Neubauer, M., \& Swedburg, R. Elements of group interaction in a real-time synchronous online learning-by-doing classroom without F2F participation. USDLA Journal, 16, 2002. http://www.usdla.or/html/journal/APR02 issue/article01.html

91. Siemens, G. Connectivism: A learning theory for the digital age. http://www.ingedewaard.net/papers/connectivism/2005 siemens ALearningTheoryForTheDigitalA ge.pdf

92. Phelps, R. Developing online from simplicity toward complexity: Going with the flow of non-linear learning. http://naweb.unb.ca/proceedings/2003/PaperPhelps.html

93. Maor, D. Using reflective diagrams in professional development with university lecturers: A development tool in online teaching. Internet and Higher Education, 9: 133-145, 2006.

94. Garrison, D.R., Anderson, T., \& Archer, W. Critical thinking, cognitive presence, and computer conferencing in distance education. American Journal of Distance Education, 15(1): 7-23, 2001.

95. Koehler, M.J., Mishra, P., \& Yahya, K. Tracing the development of teacher knowledge in a design seminar: Integrating content, pedagogy and technology. Computers \& Education, 49: 740$762,2007$.

96. Kucsera, J.V., \& Svinicki, M. Rigorous evaluations of faculty development programs. Journal of Faculty Development, 24(2): 5-18, 2010.

97. Lackey, K. Faculty development: An analysis of current and effective training strategies for preparing faculty to teach online. Online Journal of Distance Learning Administration, 14(5), 2011. http://www.westga.edu/ distance/ojdle/winter144/lackey144.html

98. Maxwell, W., \& Kazlauskas, E. Which faculty development methods really work in community colleges? Community College Journal of Research and Practice, 16(4): 351-360, 1992.

99. Hixon, E., Barczyk, C., Buckenmeyer, J., \& Feldman, L. Mentoring university faculty to become high quality online educators: A program evaluation. Online Journal of Distance Learning Administration, $14(5)$, 2011. http://www.westga.edu/ distance/ojdla/winter144/hixon_Barczyk_Buckenmeyer_feldman144.html

100. Boulemetis, J. \& Dutwin, P. The ABCs of Evaluation. San Francisco: Jossey-Bass, 2005.

\section{Appendix A}

List of Peer-Reviewed Journals That Produced Faculty Development Articles

\begin{tabular}{|l|c|}
\hline Journal Name & $\begin{array}{c}\text { Number of Articles } \\
\text { in Each Journal }\end{array}$ \\
\hline Journal of Asynchronous Learning Networks & 13 \\
\hline Internet and Higher Education & 6 \\
\hline Innovative Higher Education & 4 \\
\hline Online Journal of Distance Learning Administration & 3 \\
New Directions for Adult and Continuing Education & 2 \\
\hline Community College Journal of Research and Practice & \\
Computers \& Education & \\
Journal of Counseling \& Development & \\
Journal of Science Education and Technology & \\
Marketing Education Review & \\
MERLOT Journal of Online Learning and Teaching & \\
\hline $\begin{array}{l}\text { Academic Medicine } \\
\text { Adult Education Quarterly }\end{array}$ & \\
Advances in Management & \\
American Journal of Distance Education & \\
\hline
\end{tabular}


An Analysis of the Research on Faculty Development for Online Teaching and Identification of New Directions

Community College Review

Delta Kappa Gamma Bulletin

Educational Technology \& Society

Effective Practices for Academic Leaders

Human Architecture: Journal of the Sociology of Self-Knowledge

Information Technology and Libraries

International Journal of Hospitality Management

International Journal of Self-directed Learning

Issues in Accounting Education

Journal of Faculty Development

Journal of General Internal Medicine

Journal of Technology and Teacher Education

Medical Teacher

Metropolitan Universities

Radical Pedagogy

School Science and Mathematics

Teachers College Record

The Canadian Journal of Higher Education

The Journal

To Improve The Academy

USDLA Journal

Total Articles 